\title{
CLOSE-RANGE MINI-UAVS PHOTOGRAMMETRY FOR ARCHITECTURE SURVEY
}

\author{
L. Carnevali ${ }^{1}$, E. Ippoliti ${ }^{1}$, F. Lanfranchi ${ }^{1}$, S. Menconero ${ }^{1}$, M. Russo ${ }^{1 *}$, V. Russo ${ }^{2}$ \\ ${ }^{1}$ Dept. of History, Representation and Restoration of Architecture, Sapienza University of Rome, 00161 Rome, Italy - \\ (laura.carnevali, elena.ippoliti, fabio.lanfranchi, sofia.menconero,m.russo)@uniroma1.it) \\ ${ }^{2}$ Errealcubo Studio, 40137 Bologna, Italy - ing.valentinarusso@gmail.com
}

Commission II/WG II/2

KEY WORDS: Mini UAVs, architectonic survey, façade acquisition, data comparison, instrument validation

\begin{abstract}
:
The survey of historical façades contains several bottlenecks, mainly related to the geometrical structure, the decorative framework, the presence of natural or artificial obstacles, the environment limitations. Urban context presents additional restrictions, binding by ground acquisition activity and leading to building data loss. The integration of TLS and close-range photogrammetry allows to go over such stuff, not overcoming the shadows effect due to the ground point of view. In the last year the massive use of UAVs in survey activity has permitted to enlarge survey capabilities, reaching a deeper knowledge in the architecture analysis. In the meanwhile, several behaviour rules have been introduced in different countries, regulating the UAVs use in different field, strongly restricting their application in urban areas. Recently very small and light platforms have been presented, which can partially overcome these rules restrictions, opening to very interesting future scenarios. This article presents the application of one of these very small RPAS (less than $300 \mathrm{~g}$ ), equipped with a low-cost camera, in a close range photogrammetric survey of an historical building façade in Bologna (Italy). The suggested analysis tries to point out the system accuracy and details acquisition capacity. The final aim of the paper is to validate the application of this new platform in an architectonic survey pipeline, widening the future application of close-range photogrammetry in the architecture acquisition process.
\end{abstract}

\section{INTRUCTION}

The digital 3D survey of building façades represents a wellestablished issue, which has been improved in the last 15 years thanks to the introduction of several active and passive digital systems. In the last decade the integration of range-based and image-based survey methodologies has enhanced the acquisition process in terms of geometry and RGB data capturing, going over some limitations or bottlenecks present in the survey pipeline, enlarging their application in several architectural contexts. Unfortunately, these integrated approaches still suffer limitations, mainly due to the ground point of view, sometimes reduced raising the instruments with truck buckets, telescopic rods or viewing from a nearby windows. The introduction of light UAVs (Unmanned Aircraft Vehicle) or RPAS (Remotely Piloted Aircraft Systems) equipped with digital camera seems to be in such sense the best solution to acquire hidden or unreachable building areas, overcoming terrain limitations. The integration between high-res cameras, Computer Vision codes and RPAS has significantly increased the potentiality of this close-range photogrammetric approach. In the last years the use of these platforms to support building analysis has extremely grown, applying these systems for multi-scale acquisition campaigns in different fields. At the same time this RPAS explosion has seen in some country, i.e. in Italy, the introduction of several restrictive laws for safety purposes, which have started to regulate the use of UAVs in several field, context and operative

1 University has played the following roles: scientific coordination (L. Carnevali), archive research activity (E. Ippoliti), range-based and topographic acquisition (F. Lanfranchi), image-based data processing and writing of condition, restricting their application to very few situations and requiring only specialized flight operator. This condition is mainly evident if the case study analysed is in urban contexts, which are liable to several flight rules, de facto making almost unfeasible the application of these platforms for survey purposes. The introduction of inoffensive micro-RPAS lighter than 300 grams has opened new scenarios for close-range photogrammetry application, enlarging their use in several contexts. These new platforms, normally equipped with very small digital camera, are more subject to external weather conditions, minor steadiness and low image quality comparing with light UAVs system, elements which can affect data architecture acquisition in terms of accuracy, uncertainly, resolution, data reliability.

The problems are therefore related to the real usability of these small and very light RPAS systems to support an architectural survey. Is it possible to entrust these platforms for acquiring reliable data related both the global framework and the details distributed on a building façade, supporting architecture analysis and restitution? The paper tries to suggest a first answer to these question, proposing an experimental pipeline mainly focused to verify data reliability and resolution capability of a micro-RPAS Spark system (DJI). The UAV system is framed inside an integrated survey process with active and passive techniques applied to survey a building façade of an historical building in Bologna (Italy). The research is an outcome of university and freelance co-partnership ${ }^{1}$.

Paragraph 4 (S. Menconero), range-based and image-based data interpretation, writing of Paragraph 1,2,3,5 (M. Russo). The free-lance activity regarded UAV campaign planning and image acquisition (V. Russo).

\footnotetext{
* Corresponding author
} 


\section{STATE OF THE ART}

The range-based and image-based survey techniques are currently applied in architecture acquisition campaigns, wellknown both in scientific and applicative terms. In Italy the first experimentations of range acquisition devoted to architectures survey regard the early years of XXI Century (Addison et al. 2000; El-Hakim et al. 2003) but they have seen a very quick and rapid growth in the last 15 years, thanks to several experimental application in Cultural Heritage fields, as archaeology (Guidi et al. 2006), architecture (Gaiani, 2001; Bianchini et al. 2003), sculpture (Levoy et al. 2000; Bernardini et al. 2002) and Design one (Guidi et al. 2010).

On the other hand, processing unstructured point clouds from range instruments has not improved significantly in the last decade and it is essentially still based on clouds alignment with target or iterative closest point (ICP) algorithm (Besl et al. 1992; Chen et al. 1992), data filtering, and meshing through reverse and range-based modeling processes.

Close range photogrammetry is more deep-rooted in the survey activity (Kraus, 2007; Luhmann et al. 2014), even if it has boosted its importance with the introduction of software which easily support both digital photogrammetric pipeline and the image-based modeling activity (Remondino et al. 2006; Remondino et al. 2014). These software, mostly based on automatic procedures, are nowadays used in several application field, even if they present some blackbox in data processing and lacks in managing each single step. Some research in such direction have been carried out, deeply analysing both data process (Remondino et al. 2013) and conclusive results coming out from different platforms (Murtiyoso et al. 2017).

In recent years the integration between high-res cameras, Computer Vision codes and RPAS have significantly increased the potential of this photogrammetric technique (Vosselman, 2010), in particular regarding mini-UAVs or micro-RPAS (Turner et al. 2012, Bolognesi et al. 2014, Nex et al. 2014), opening to the possible integration between aerial and terrestrial close-range images.

The use of UAVs has seen a first widespread in the archaeology survey field, providing a general and never seen before point of view of the whole surroundings (Fernandez-Hernandez et al. 2015; Remondino et al. 2011), using either fixed-wing (Suwardhi et al. 2015) or a rotary-wing UAV (Chiabrando et al. 2015). Another application of UAVs is related to close-range modeling or inspection of buildings by using the rotary-wing type (Caroti et al. 2015; Cefalu et al. 2013; Wenzel et al. 2013), a methodology often integrated with the terrestrial passive and active acquisition. (Achille et al. 2015; Grenzdörffer et al. 2015). The acquisition and interpretation of digital data has forced to understand and manage this new kind of knowledge, introducing in the same time a sort of digital divide between technical and humanistic competence. For this latter reason it is useful to test instruments and methodologies, verifying from one side their metrological reliability, from the other producing intelligible results for non-technical people, creating a knowledge connection between different application fields (Stylianidis et al. 2016).

Nowadays, 3D survey workflow applied for the urban façades acquisition is not a novelty, nevertheless it presents several "bottlenecks" in critical environmental conditions (Toschi et al. 2017), such as the historical city centres, which are strongly bound by each country set of rules (Stoker et al. 2017), particularly pressing in the Italian country (ENAC, 2016). Very few survey experimentations have adopted ultra-light UAVs for surveying architecture case study (Russo et al. 2018) but this field open very interesting scenarios in terms of testing methodology, giving the opportunity to widen close-range photogrammetry applications, introducing another important chance from the research point of view.

\section{CASE STUDY}

Villa Aldrovandi Mazzacorati stands on the territory of Camaldoli's estate, acquired by Annibale Marescotti in 1616. In that period the land was used for agricultural purposes, with a little and modest owners' home. A few years later, in 1690, the noble dwelling with its garden passed to Aldrovandi family by inheritance. Despite some house transformations has been carried out, it maintained its single-storey structure almost unchanged. In 1761 important transformation works has been started. In 1763 a little theatre inside the palace was inaugurated with two orders of lodges supported by caryatids and telamons made by Tadolini, with busts by Balugani and paintings by Basoli. This theatre had a leading role for the diffusion of the Italian Theatre culture, thanks to the frequent representations of the most famous companies of that time (Calore, 2004). In 1765 the second floor of the villa was raised by Francesco Tadolini's project, inspired by the neoclassical modules with the central six-columned portico, tympanum and semi-elliptical porticoed wings (Guidicini, 1868).

This architectonical configuration reminds the Venetian Villa inspired by Palladio (i.e. Villa Badoer) translated by the stylistic rules of Bologna area. At the end of the 18th century the building became property of the Marquises Mazzacorati, who preserved the actual architecture and surroundings. Today a solemn entrance gate leads to an Italian garden which frames the Villa, with two meadows and fountains. Currently the villa, in addition to the theatre still in use, houses offices and clinics of health and social services in the city of Bologna. Inside the villa there is also the "Mario Massacesi" Historical Museum of Soldatino, which collects more than 12000 pieces of soldiers in various materials built since 1800 .

The actual building (Figure 1) contains different interesting aspects which make it suitable for the survey experimentation. From the architectonical point of view, the main façade analysed refers to a neoclassic style, so it contains several sculptural elements (capitals, friezes, tympanum, balustrades, dripstones) framed in an articulated architectonic structure. The building surroundings have pledged a suitable working condition, due to the park area and consequent presence of a wide space in front of the Villa.

Despite this appropriate working condition, the application of any single survey methodology bounded to the ground would have led to several lacks in data acquisition. In fact, the geometrical complexity of the façade and the presence of an articulated decorative framework should lead to evident shadows effects, extended by the presence of a building yard and consequent artificial occlusions. Another obstacle for the optical survey approach is represented by the anti-fall protection net, which covers part of narthex aperture and the complete tympanum area (Figure 2). At the end, the variation of scale from the façade and the single decoration requires a multi-scale approach, foreseeing a suitable sampling step both for the whole façade and the single sculptural elements.

All these characteristics lead to plan a multi-resolution survey campaign based on active and passive techniques, covering as much possible façade surface with a suitable sampling step, in the meanwhile having redundant data useful for a comparison step and data validation. 

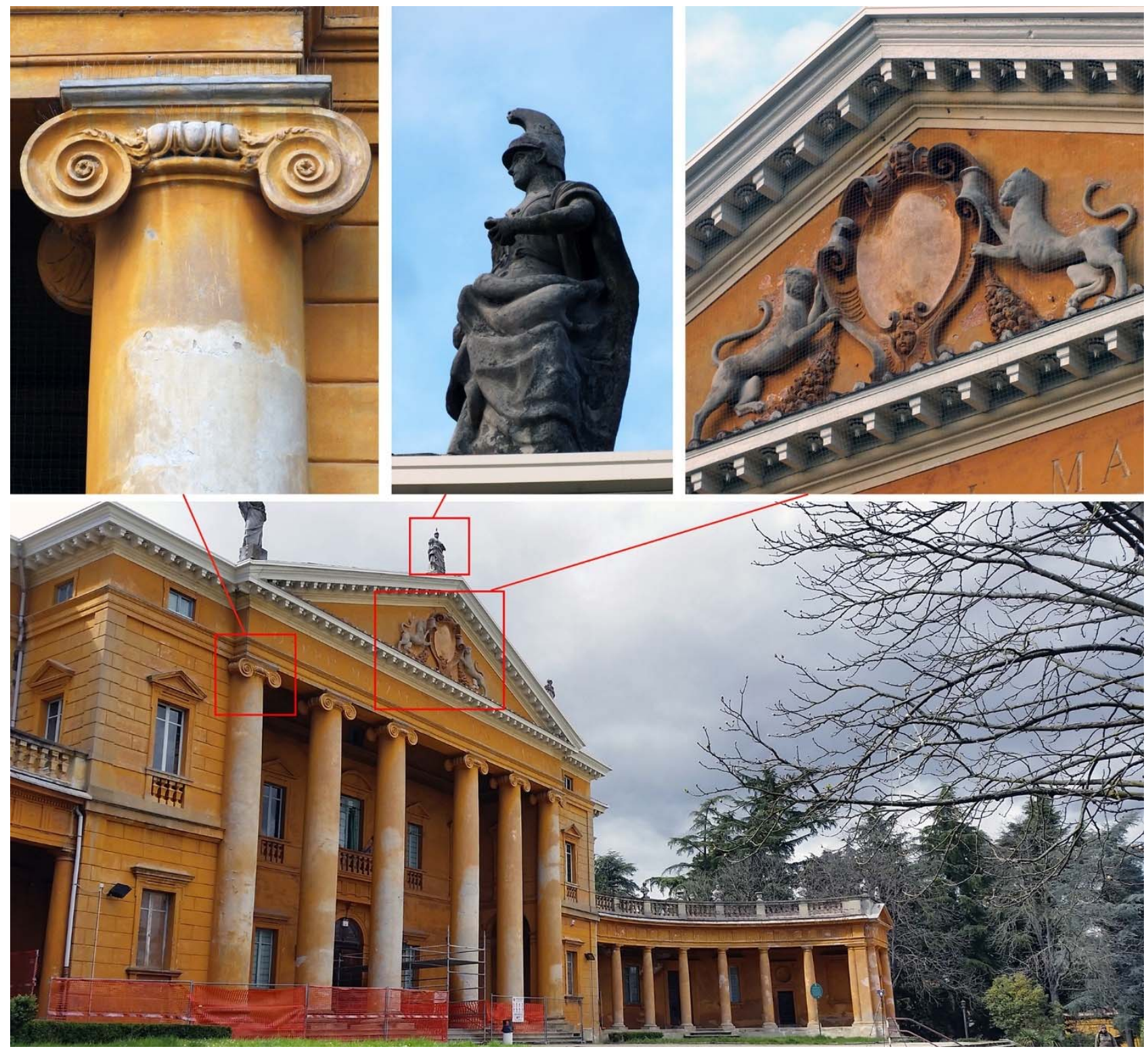

Figure 1. Pictures of the main façade of Villa Aldrovandi Mazzacorati and some architectonic and sculptural details.

A multi-resolution survey approach need to face and solve acquisition problems linked both the global structure and its details survey. But the integration between image-based and range-based acquisition approaches from the ground is not suitable and adequate to sample all the façade survey for shadow effects. In addition, the presence of several sculptural elements framed in the upper part of the façade of 29,3 x 19,6 meters doesn't allow to complete the façade acquisition, even adopting a close-range photogrammetry approach based on the use of both digital camera from the terrain point of view and mounted on a telescopic rod. Starting from the clear limitations showed by a survey solution based on active and passive techniques framed in a "standard" acquisition process, a photogrammetric approach based on RPAS was considered the best solution. In fact, it can perform an high density and coherent acquisition of the whole façade, reducing the shadows affect and preserving the complex and distributed sculptural details.

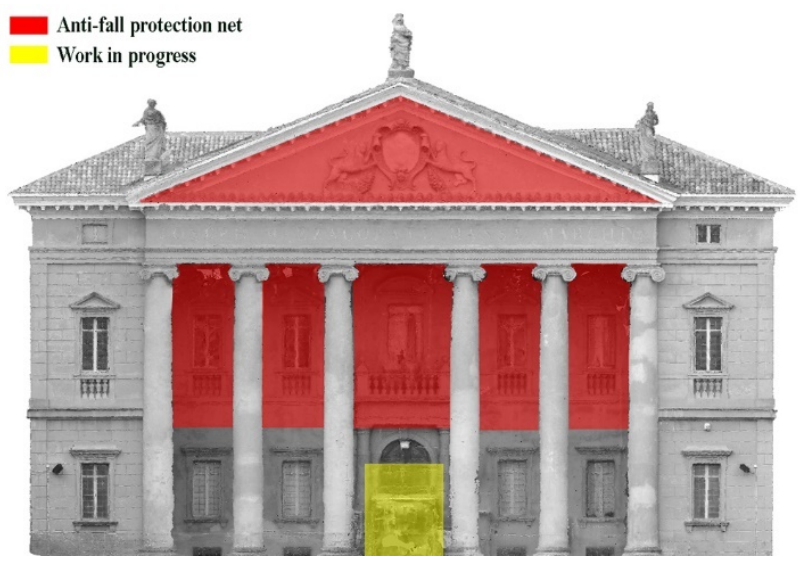

Figure 2. Survey artificial obstacles schema.

\footnotetext{
* Corresponding author
} 


\section{SURVEY AND MODELING}

\subsection{Acquisition methodology}

The photogrammetric survey of the façade was performed through a DJI Spark UAV and its integrated camera. The small UAV (Figure 3) is equipped with propeller guards, compulsory to operate in critical scenarios, having a take-off weight of $340 \mathrm{~g}$. Therefore, to operate in the urban area complying with the maximum allowed weight, the aircraft was slightly lightened just below $300 \mathrm{~g}$. (Table 1)

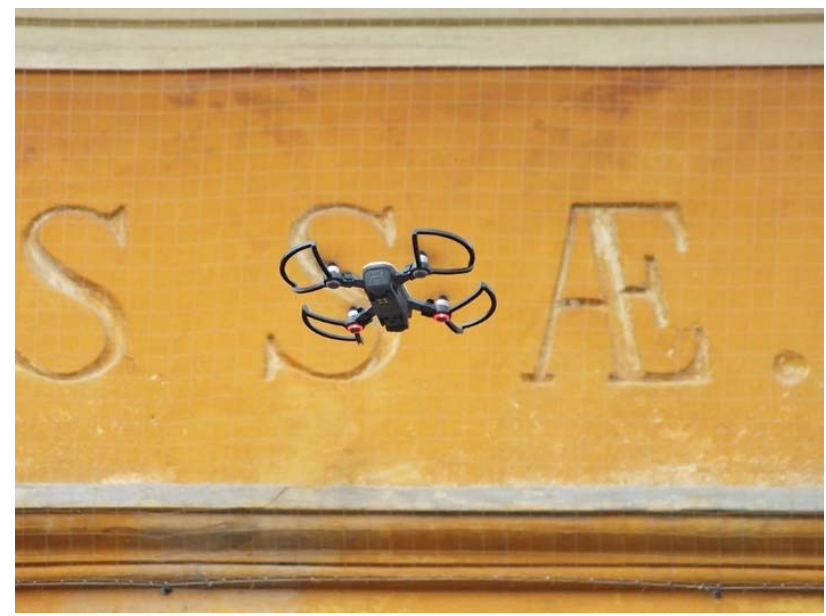

Figure 3. DJI Spark during one of the flight missions.

Even if the survey was planned inside an urban park, with a more suitable operative condition respect to a standard urban UAVs acquisition, all ENAC rules have been followed by the RPAS pilot. The survey has been planned during the public offices and clinics closing time, to avoid any interference between survey activities and people passage, pledging a safe operating condition.

To obtain the best solution in terms of geometrical acquisition, different flights were planned. The survey of the whole façade was carried out considering a constant distance of about $10 \mathrm{~m}$ between RPAS camera and façade, evaluating carefully both the flight time and the global number of shots required to cover all the building surface, obtaining an average Ground Sample Distance (GSD) of $4 \mathrm{~mm}$. The images were captured with a baseline of $2 \mathrm{~m}$ along the single vertical paths, to ensure an average overlapping of $80 \%$ in the vertical direction. These paths were fixed at 6 meters distance, obtaining an overlap of $60 \%$ in horizontal direction, covering the whole surface with 7 vertical paths (Figure 4). The overlap considered have been much higher in the flight direction because a manual flight has been carried on and it has been difficult to respect the programmed trajectory and maintain a constant speed in manual driving configuration. For each RPAS hovering stop, three different superimposed images have been acquired, the first one with axe perpendicular to the façade, the other two with sloped axis in right and left direction, covering a global field of view of approximatively $180^{\circ}$. An embedded proximity sensor helped to maintain the proper distance from the façade to comply with the flight plan as much as possible.

An additional acquisition campaign has been planned, devoted to survey the entrance steps of the palace partially hidden by work in progress. For the tympanum survey, a similar approach has been followed, covering the whole area with a sequence of 4 nadiral images distributed in each vertical column for 12 vertical paths, following the same overlapping rules. In this survey acquisition a mean distance of $2 / 3$ meters has been considered, performing a finale GSD of $1 \mathrm{~mm}$.

\begin{tabular}{|l|c|}
\hline \multicolumn{2}{|c|}{ Aircraft specifications* } \\
\hline Take-off weight (g) & 300 \\
\hline Dimensions $(\mathrm{mm})$ & $143 \times 143 \times 55$ \\
\hline Max flight time (min) & 16 (no wind) \\
\hline Operating temperature range $\left({ }^{\circ} \mathrm{C}\right)$ & $0-40$ \\
\hline Maximum work range $(\mathrm{km})$ & $1-2$ \\
\hline Satellite Positioning System & GPS/GLONASS \\
\hline Hover accuracy range - Horizzontal $(\mathrm{m})$ & $+/-0.3$ \\
\hline Hover accuracy range - Vertical $(\mathrm{m})$ & $+/-0.1$ \\
\hline \multicolumn{2}{|c|}{ Camera specifications } \\
\hline Sensor format Flight Plan parameters \\
\hline Sensor & $6.16 \times 4.60$ \\
\hline Lens & $1 / 2.3{ }^{\prime} \mathrm{CMOS}$ \\
\hline ISO range & FOV $81.9^{\circ}$ \\
\hline Image resolution (px) & $100-1600$ \\
\hline Pixel size $(\mu \mathrm{m})$ & $3968 \times 2976$ \\
\hline Focal length (mm) & 1.55 \\
\hline Diagonal crop factor & 4.49 \\
\hline \multicolumn{2}{|c|}{5.6} \\
\hline Near to far façade flying distance (m) & $2-10$ \\
\hline Near to far GSD (mm) & $3.1 \times 2.3$ \\
\hline Area covered by near image $(\mathrm{m})$ & $15.4 \times 11.5$ \\
\hline Area covered by far image $(\mathrm{m})$ & $80 \%$ \\
\hline Vertical overlap (along flight line) & $60 \%$ \\
\hline Lateral overlap & \\
\hline
\end{tabular}

Table 1. DJI Spark specifications (*from www.dji.com) and flight plan Parameters.

In this case no sloped images have been planned, considering the $81,9^{\circ}$ camera field of view sufficient to sample the whole surface. At the end two different single photogrammetric campaigns have been carried on, acquiring single sculptural examples, like a capital and a statue in the upper part of the façade. In both these latter cases, a sequence of convergent images around the detail were acquired at a survey distance of $2 / 3$ meters.

Manual flight missions were performed for all photogrammetric campaigns, capturing different image sets with fixed exposure value of 1/500 and ISO 400. The total time spent for UAV data acquisition was about 1 hour, considering both the architectonic survey and the sculptural one: a total number of 189 images were taken to sample the whole façade, covering an area of about 35 $\mathrm{m}$ wide $\times 23 \mathrm{~m}$ high, while 84 images were used for the detailed tympanum survey, 10 images for the capital and 18 for the statue (Table 2). Regarding camera calibration, a self-calibration approach was adopted testing the simplest survey procedure, modeling the radial distortion with the Brown's model, even if some authors recommend more robust camera calibration.

A topographic campaign has been planned at the end of the photogrammetric survey, to acquire GCP photogrammetric reference points on the façade (Figure 5).

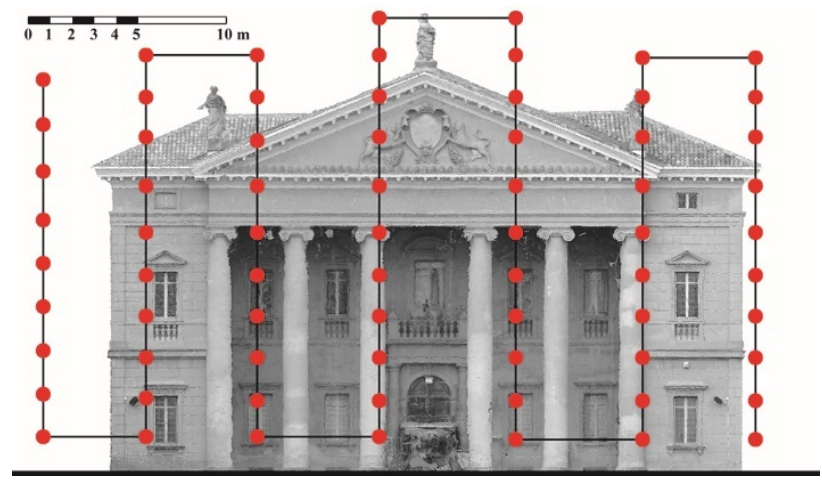


Figure 4. Flight plan for the whole façade with acquisition shots.

A total of 31 points identified by architectural features on the external walls of the building were surveyed by a Geomax Zoom 35 Pro total station from a local network established in front of the building. The topographic survey required one hour. At the end, a phase shift 3D laser scanner (Focus 3D, Faro) has been used to acquire from the ground a sequence of scans, creating a reference point clouds which can be used to verify the global quality of the photogrammetric campaign. In the range-imaging planning 5 different scans has been considered, with a mean working distance of 16 meters from the façade: one central scan with a $4 \mathrm{~cm}$ sampling step, four lateral ones with a resolution of $8 \mathrm{~cm}$. The 3D scanning survey required one hour.

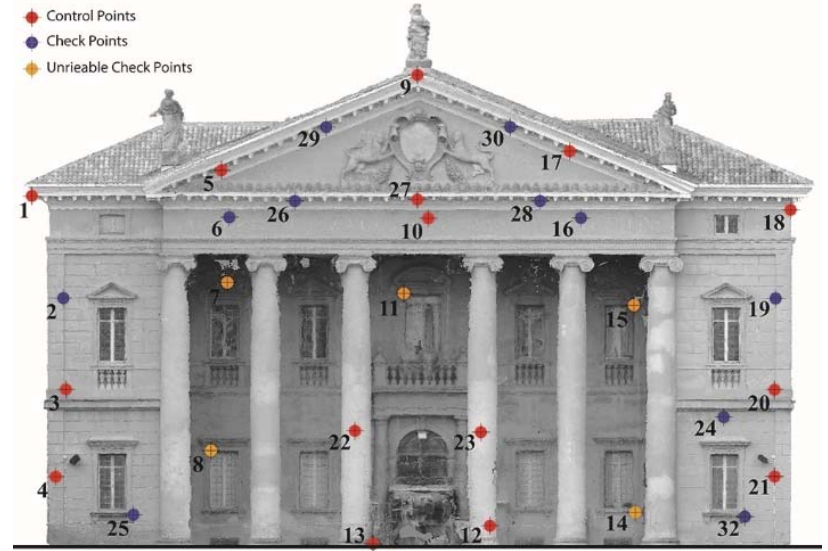

Figure 5. GCPs network distributed on the façade.

\subsection{Data process}

Photogrammetric data were processed by the commercial software PhotoScan Professional (Agisoft), assuming the computation parameters listed in Table 4. During the image orientation step, 14 photogrammetric reference points were used as control points for the bundle adjustment, framing the entire data set in the topographic network and minimizing the orientation errors.

The presence of different dark images in the image set, due to the camera set-up and the limitation in acquiring shaded surface, has implied a higher time in selecting GCP, affecting also the precision in their recognition (Figure 6, Table 3).

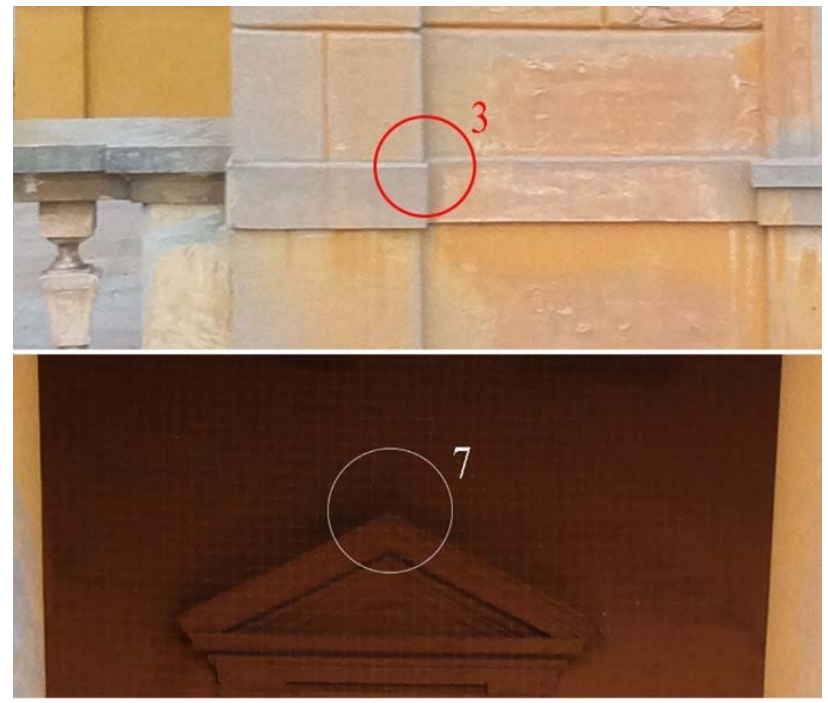

Figure 6. Distinct levels of GCPs recognizability in relation with their façade position.

The maximum alignment residual computed on the control points after the bundle adjustment is $4.7 \mathrm{~cm}$ as spatial vector relative to the point 13 , while the maximum XYZ component is $2.9 \mathrm{~cm}$ in $\mathrm{X}$ direction (approximately parallel to the façade) for the point 5 . The root mean square value of the entire orientation project is 3.2 $\mathrm{cm}$. The resulting photogrammetric dense cloud of the whole façade, obtained through the photogrammetric and SfM workflow built with the parameters shown in Table 4, consisted of about 23 million points (Table 2). All the SfM process to obtain the final dense cloud required $23 \mathrm{hr}$.

A similar process has been followed to process images related to the tympanum, introducing the topographic GCPs in order to orient in the same reference system the detailed survey, obtaining a multi-resolution 3D model. In this case any quality check was carried on, evaluating the metrological aspect only for the whole façade. A post-processing of 15 hours has allowed to obtain a dense cloud of 21.5 million of points (Table 2).

Images related to the capital and statue were than processed separately, creating two different 3D model. These images were firstly oriented in the tympanum project before introducing GCPs, completing the multiresolution model (Table 2).

\begin{tabular}{|l|c|c|c|}
\hline \multicolumn{4}{|l|}{ Global facade } \\
\hline \# Img & Tie Points & \# Dense Points & \# Polygon \\
\hline 189 & 48.570 & 23.181 .000 & 4.588 .000 \\
\hline Tympanum \\
\hline 84 & 42.750 & 21.554 .000 & 4.310 .000 \\
\hline Capital \\
\hline 10 & 4620 & 1.760 .000 & 4.700 .000 \\
\hline Statue & & \\
\hline 18 & 20.180 & 1.900 .000 & 4.325 .000 \\
\hline
\end{tabular}

Table 2. Points and polygon created during SfM process

The final TLS point clouds were registered through ICP algorithms and framed in the same reference system of the photogrammetric dense cloud, thanks to the same GCPs, applying a six-parameters transformation (invariant scale). Due to the evident presence of lots of sculptural and architectonic elements and the building dimension, several shadow areas were present in the final range point cloud, which didn't affect the role of gold standard in the comparison phase.

\subsection{Data comparison}

Data comparison and quality check have been performed in two distinct phases, carrying on a geometrical analysis and a quality check. The first one was addressed from one side to a punctual evaluation of the distance between GCPs and relative photogrammetric points, from the other a global evaluation on the geometrical reliability of the whole dense point clouds obtained at the end of the SfM process, comparing range-based and image-based data. As previously explained, a set of check points surveyed with a total station was used to assess the accuracy of the photogrammetric model, obtaining average values of the residuals compatible with the respective ones computed on the control points (Table 3).

The analyses started from the identification of the 17 topographic points on the images, using them as check points to perform a first validation of the photogrammetric model. Higher residuals values were detected on the check points respect to the orientation points, with a RMS of $5.0 \mathrm{~cm}$, but some points located under the narthex have showed very high values, probably due to both the minor detecting precision carried on in the dark images 
and the lower images overlapping, with relative definition of few projections.

\begin{tabular}{|l|c|c|c|c|}
\hline \multicolumn{2}{|c|}{ Control Points } & & \multicolumn{2}{c|}{ Check Points } \\
\hline Points & Error $(\mathrm{m})$ & & Points & Error $(\mathrm{m})$ \\
\hline 1 & 0.04 & & 2 & 0.03 \\
3 & 0.02 & & 6 & 0.02 \\
4 & 0.02 & & 7 & 0.12 \\
5 & 0.04 & & 8 & 0.12 \\
9 & 0.02 & & 11 & 0.10 \\
10 & 0.02 & & 14 & 0.08 \\
12 & 0.04 & & 15 & 0.11 \\
13 & 0.05 & & 16 & 0.02 \\
17 & 0.02 & & 19 & 0.02 \\
18 & 0.02 & & 24 & 0.03 \\
20 & 0.03 & & 25 & 0.05 \\
21 & 0.04 & & 26 & 0.02 \\
22 & 0.02 & & 27 & 0.01 \\
23 & 0.03 & & 28 & 0.02 \\
& & & 29 & 0.03 \\
& & & 30 & 0.02 \\
& & & 32 & 0.04 \\
\hline Mean Error & $\mathbf{0 . 0 3}$ & & \multicolumn{2}{|c|}{} \\
\hline
\end{tabular}

Table 3. Control and check points 3D residuals.

In fact, excluding these points from the RMS residual calculation of the check point, the RMS value obtained is $3 \mathrm{~cm}$, compliant with the orientation residual one. To perform a further and more effective validation of the photogrammetric survey, a reference model of the façade realized by TLS was compared with the photogrammetric point cloud in Cloud Compare software, highlighting the deviations in the different areas of the façade between them, using an appropriate colormap. The colour scale indicates deviations between 0 and $25 \mathrm{~cm}$. The analysis showed a good congruence between clouds related to the near façade, with absolute deviations which do not exceed $5 \mathrm{~cm}$. But there are some areas located under the narthex where the differences reach values ranging from 5 to $25 \mathrm{~cm}$ (Figure 7), due to a lower image coverage and a greater difficulty in image orientation, which led to a noisier data. Even if present, no laser scanners shadows have influenced this comparison, since the deviations were computed for each point of the laser scanner cloud, exploiting the high density of both clouds.

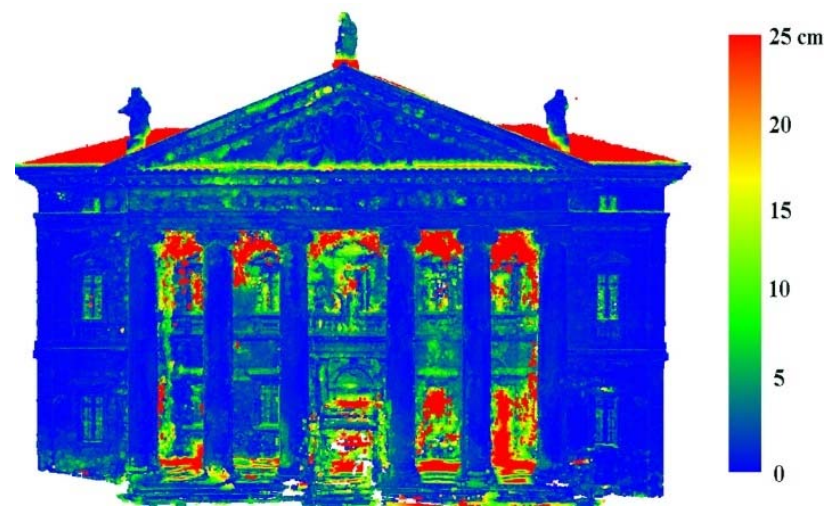

Figure 7. Data comparison between TLS and photogrammetric point clouds

Once the dense photogrammetric cloud has been validated, a textured decimated mesh of 4.6 million of polygon of the whole façade has been generated, in order to build an ortho-mosaic image (Figure 8). The resulting orthophoto of the façade has a global GSD of 3,6 mm, according with the $4 \mathrm{~mm}$ sampling step of the initial images. The same activity has been carried out to create the $3 \mathrm{D}$ polygonal model of the tympanum, the capital and the statue, obtaining a decimated models of about 4.5 million of polygons for each element (Table 2). The quality analysis carried out on the final model, mainly based on their visualization in virtual environment, has allowed to test the capability of the survey approach to acquire detail, creating high density $3 \mathrm{~d}$ model of single artefacts framed inside a building façade (Figure 9).

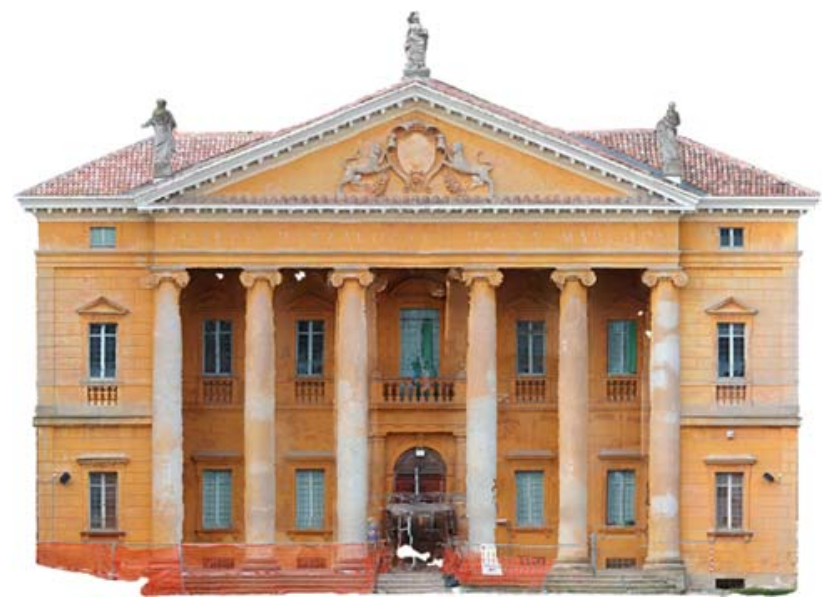

Figure 8. Ortho-mosaic of the building façade.

\begin{tabular}{|l|l|}
\hline \multicolumn{2}{|c|}{ Orientation } \\
\hline Accuracy & High \\
\hline Pair selection & Disabled \\
\hline Key point limit & 200000 \\
\hline Tie point limit & 50000 \\
\hline \multicolumn{2}{|c|}{ Reference settings } \\
\hline Marker accuracy (m) & 0.005 \\
\hline Marker accuracy (pix) & 1 \\
\hline Tie point accuracy (pix) & 2 \\
\hline \multicolumn{2}{|c|}{ Dense cloud building } \\
\hline Quality (façade) & High \\
\hline Quality (details) & Ultra-High \\
\hline Depth filtering and texturing \\
\hline \multicolumn{2}{|c|}{ Mild } \\
\hline Number of polygon & High \\
\hline Façade texture (pix) & 4096 x 4096 \\
\hline Details texture (pix) & $2048 \times 2048$ \\
\hline
\end{tabular}

Table 4. Computation parameters used in Photoscan.

\section{CONCLUSION}

The results presented in this article showed that a survey of a complex façade carried on with a small RPAS like the DJI Spark is feasible. In particular, the final results showed from one side a reliable orthoimage of the façade with a geometrical quality suitable for its subsequent drawing representation, from the other some high-res 3D polygonal models useful for architectonic details analysis and representation.

The quality check carried on between photogrammetric points and topographic reference data has reported a mean RMS values of $3 \mathrm{~mm}$, while the comparison between the UAV point clouds and TLS reference one highlighted a deviation of few centimetres, demonstrating a fine quality in terms of data accuracy and reliability. Only the façade under the narthex presented higher deviations, due to the survey condition which led to a lower quality in terms of orientation, point definition, 
increasing the surface noise. Instead, the anti-fall protection net has no affected the quality of geometrical acquisition. In general, to go over the highlighted limitations and reaching a compliant knowledge of the building, the best survey solution is still defined by the integration between active and passive methodologies, using UAV with high-res camera if it is permitted. But the experimental campaign described in this paper has demonstrated that this small UAV typology equipped with low-cost digital cameras can open new scenarios, leading to an almost complete acquisition of an architectural subject, where both ground photogrammetry and laser scanning provide unsatisfactory result, going over several operating limitations. Regarding future research, some additional tests must be planned to refine a suitable methodology, with the awareness that future sensors development will help in reaching higher results, likely adding to the survey path a very important instrument of architectural knowledge, preserving in the meanwhile the possibility to create multi-resolution reliable 3D models.

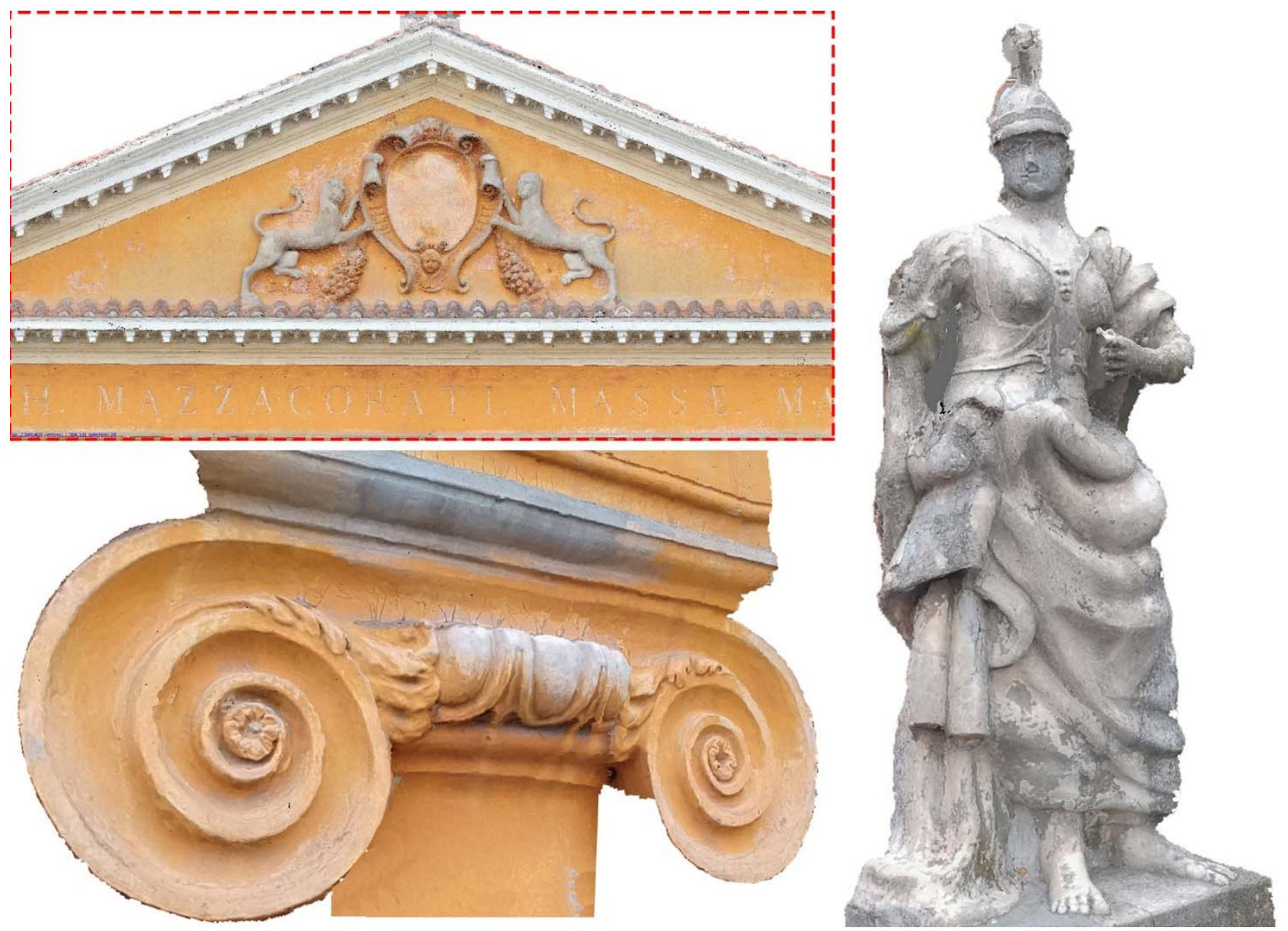

Figure 9. 3D image-based models of tympanum decoration, capital and the central-upper statue over the roof.

\section{REFERENCES}

Achille, C., Adami, A., Chiarini, S., Cremonesi, S. Fassi, F., Fregonese, L., and Taffurelli, L., 2015. UAV-based photogrammetry and integrated technologies for architectural applications - Methodological strategies for the after-quake survey of vertical structures in Mantua (Italy). Sensors, 15 (12), pp. $15520-39$.

Addison, A. C., and Gaiani, M., 2000. Virtualized architectural heritage: New tools and techniques. IEEE Multimedia, 7 (2), pp. 26-31.

Bernardini, F., and Rushmeier, H., 2002. The 3D model acquisition pipeline. Computer Graphics Forum, 21 (2), pp. 14972 .

Besl, P., and McKay, N. D., 1992. A method for registration of 3-D shapes. IEEE Transactions Pattern Analysis Mach Intelligent, 14, pp. 239-256.
Bianchini, C., Paolini, P., 2003. Rilievo per il restauro e la messa in sicurezza di Hagia Sophia a Istanbul: prime sperimentazioni. Disegnare, Idee, Immagini, 26, pp. 20-31.

Bolognesi, M., Furini, A., Russo, V., Pellegrinelli, A., and Russo, P., 2014. Accuracy of cultural heritage 3D models by RPAS and terrestrial photogrammetry. In: The International Archives of the Photogrammetry, Remote Sensing and Spatial Information Sciences, XL-5:113-19.

Calore, M., 2004. Storie di teatri, teatranti e spettatori, Bologna Comune di Bologna

Caroti, G., Martınez-Espejo Zaragoza, I., and Piemonte, A., 2015. Accuracy assessment in structure from motion 3D reconstruction from UAV-born images: The influence of the data processing methods. In: International Archives of Photogrammetry, Remote Sensing and Spatial Information Sciences, XL-1/W4 (1), pp. 103-09. 
Cefalu, A., Abdel-Wahab, M., Peter, M., Wenzel, K., and Fritsch, D., 2013. Image based 3D reconstruction in cultural heritage preservation. In: 10th International Conference on Informatics in Control, Automation and Robotics, pp. 201-205.

Chen, Y., Medioni, G., 1992. Object modelling by registration of multiple range images. Image and Vision Computing, 10 (3), pp. $145-55$.

Chiabrando, F., Donadio, E., Rinaudo, F., 2015. SfM for orthophoto generation: A winning approach for cultural heritage knowledge. In: International Archives of Photogrammetry, Remote Sensing and Spatial Information Sciences, XL-5/W7 (5), pp. 91-98.

El-Hakim, S., Beraldin, J-A., Picar, M., Vettore, A., 2003. Effective 3D Modeling of Heritage Sites. In: 4th International Conference of 3D Imaging and Modeling (3DIM'03), pp. 302309.

ENAC (Ente Nazionale per l'Aviazione Civile). 2016. Regolamento sui mezzi aerei a pilotaggio Remoto. Rome: ENAC

Fernández-Hernandez, J., González-Aguilera, D., RodriguezGonzálvez, P., Mancera-Taboada, J., 2015. Image-based modelling from unmanned aerial vehicle (UAV) photogrammetry: An effective, low-cost tool for archaeological applications. Archaeometry, 57 (1):128-45.

Gaiani, M., 2001. Traduzione dal reale al virtuale in architettura - Un metodo integrato di acquisizione dati e costruzione di modelli digitali tridimensionali. In: Migliari Riccardo (a cura di). Frontiere del rilievo: dalla matita allo scanner 3D, Roma: Gangemi Editore, p. 71-85.

Grenzdörffer, G. J., Naumann, M., Niemeyer, F., Frank, A., 2015. Symbiosis of UAS photogrammetry and TLS for surveying and 3D modeling of cultural heritage monuments - A case study about the Cathedral of St. Nicholas in the city of Greifswald. In: International Archives of Photogrammetry, Remote Sensing and Spatial Information Sciences, XL-1/W4 (1), pp. 91-96.

Guidi, G., M. Russo, and A.-J. Beraldin. 2010. Acquisizione 3D e modellazione poligonale, Milan: McGraw Hill.

Guidi, G., Frischer, B., Russo, M., Spinetti, A., Carosso, L., Micoli, L.L., 2006. Three-dimensional acquisition of large and detailed cultural heritage objects. Machine Vision and Applications, Amsterdam: Elsevier, 2006, 17 (6), pp. 349-360.

Guidicini, G., 1868. Cose notabili della città di Bologna ossia Storia cronologica de' suoi stabili sacri, pubblici e privati, Forni, Bologna

Kraus, K., 2007. Photogrammetry: Geometry from images and laser scans, 2nd ed. Berlin, Germany: Walter de Gruyter.

Levoy, M., Pulli, K., Curless, B., Rusinkiewicz, S., Koller, D., Pereira, L., Ginzton, M., Anderson, S., Davis, J., Ginsberg, J., Shade, J. Fulk, D., 2000. The digital michelangelo project: 3D scanning of large statues. In: Proceedings of ACM SIGGRAPH, pp. 131-44.

Luhmann, T., Robson, S., Kyle, S., Boehm, J., 2014. CloseRange photogrammetry and $3 D$ imaging, 2nd ed., 684. Berlin, Germany: De Gruyter.
Murtiyoso, A., Grussemmeyer, P., 2017. Documentation of heritage buildings using close-range UAV images: Dense matching issues. Comparison and Case Studies. The Photogrammetric Record, 32 (159), pp. 206-29.

Nex, F., Remondino, F., 2014. UAV for 3D mapping applications: A review. Applied Geomatics, 6 (1), pp. 1-15.

Remondino, F., Spera, M.G., Nocerino, E., Menna, F., Nex, F., 2014. State of the art in high density image matching. Photogrammetric Record, 29 (146), pp. 144-66.

Remondino, F., Spera, M.G., Nocerino, E., Menna, F., Nex, F., Gonizzi-Barsanti, S., 2013. Dense image matching: Comparisons and analyses. In: Proceedings of the Digital Heritage International Congress 2013, (1), pp. 47-54.

Remondino, F., Barazzetti, L., Nex, F., Scaioni, M., Sarazzi, D., 2011. UAV photogrammetry for mapping and 3D modeling Current status and future perspectives. In: International Archives of Photogrammetry, Remote Sensing and Spatial Information Sciences, 38 (1/C22), pp. 25-31.

Remondino, F., El-Hakim, S., 2006. Image-based 3D modelling: A review. The Photogrammetric Record, 21 (115), pp. 269-91.

Russo, M., Carnevali, L., Russo, V., Savastano, D., Taddia, Y., 2018. Modelling and Deterioration Mapping of Façades in Historical Urban context by Close Range Ultra-Lightweight UAVs Photogrammetry. International Journal of Architectural Heritage, pp. 1-21.

Stöcker, C., Bennett, R., Nex, F., Gerke, M., Zevenbergen, J., 2017. Review of the current state of UAV regulations. Remote Sensing, 9 (459), pp. 1-26.

Stylianidis, E., Remondino, F., 2016. $3 D$ recording, documentation and management of cultural heritage. Dunbeath, Caithness: Whittles Publishing.

Suwardhi, D., Menna, F., Remondino, F., Hanke, K., Akmalia, R., 2015. Digital 3D Borobudur - Integration of 3D surveying and modeling techniques. In: International Archives of Photogrammetry, Remote Sensing and Spatial Information Sciences, XL-5/W7 (5), pp. 417-423.

Toschi, I., Ramos, M.M., Nocerino, E., Menna, F., Remondino, F., Moe, K., Poli, D., Legat, K., Fassi, F., 2017. Oblique photogrammetry supporting 3D urban reconstruction of complex scenarios. In: International Archives of the Photogrammetry, Remote Sensing and Spatial Information Sciences, XLII-1/W1 (1), pp. 519-526.

Turner, D., Lucieer, A., Watson, C., 2012. An automated technique for generating georectified mosaics from ultrahigh resolution Unmanned Aerial Vehicle (UAV) imagery, based on Structure from Motion (SFM) point clouds. Remote Sensing, 4 (12), pp. 1392-1410.

Vosselman, G., Maas, H.G., 2010. Airborne and terrestrial laser scanning. Caithness: Whittles.

Wenzel, K., Rothermel, M., Fritsch, D., Haala, N., 2013. Image acquisition and model selection for multi-view stereo. In: International Archives of Photogrammetry, Remote Sensing and Spatial Information Sciences, XL-5/W1 (5), pp. 251-58. 